\title{
Characterization of the structure of rice and wheat straw pretreated with Trichoderma sp. AH
}

\author{
Xin $\mathrm{Xu}^{1}$, Quan-Xi Zheng ${ }^{1}$, Li Guo ${ }^{1}$, Ji-XIn $\mathrm{Mao}^{1}$, and Jian-Qiang $\mathrm{Hu}^{1}$
}

${ }^{1}$ Air Force Logistics College

September 28, 2020

\begin{abstract}
In this study, the effect of PT with Trichoderma sp. AH on structure of rice wheat (RS) and wheat straw (WS) was investigated. TG/DTG analysis shows that PT could incompletely degrade RS and WS with no significant effect on their group composition. XRD analysis shows that PT could incompletely destroy the crystal structure of RS and WS causing lower crystallinity, which clearly suggests that PT is effective in disrupting the structure. The effect of PT on RS and WS is primarily on cellulose and hemicelluloses decrystallization to amorphous material. XPS analysis shows that PT has some influence on the oxygen- and nitrogen-containing compounds with increasing the relative contents of some oxygen- and nitrogen-containing compounds. PT is an effective preparation for biomass liquefaction by destroying the structure of biomass with minimal loss of carbohydrates.
\end{abstract}

\section{Hosted file}

manuscript-AJ.pdf available at https://authorea.com/users/362590/articles/483737characterization-of-the-structure-of-rice-and-wheat-straw-pretreated-with-trichoderma$\mathrm{sp}-\mathrm{ah}$ 